\title{
Water Risk Assessment in Supply Chains.
}

\author{
Torben Schaefer ${ }^{1}$, Maximiliano Udenio*2 ${ }^{2}$, Shannon Quinn ${ }^{1}$, and Jan C. Fransoo ${ }^{3,4}$ \\ ${ }^{1}$ The Procter \& Gamble Company, 1 Procter \& Gamble Plaza, Cincinnati, Ohio \\ 45202, USA \\ ${ }^{2}$ Research Center for Operations Management, KU Leuven, 3000 Leuven, Belgium \\ ${ }^{3}$ Kuhne Logistics University, Grosser Grasbrook 17, Hamburg 20457, Germany \\ ${ }^{4}$ Eindhoven University of Technology, Den Dolech 2, 5600MB Eindhoven, The \\ Netherlands
}

Total word count: 8498 .

\begin{abstract}
Sustainability has long been recognized as a fundamental practice in manufacturing. In recent years, firms have been devoting resources to reduce their carbon footprint, greenhouse gas emissions, and water use. However, the problem of measuring and acting upon water risk in the supply chain has not yet been tackled in the literature. Unlike other environmental concerns, water risk is a local phenomenon that needs to be quantified at the catchment level. Thus, the impact of a production process cannot be location-agnostic and must be analyzed within its particular context-ideally at the production site level. Furthermore, recent trends in manufacturing (such as "local production") are expected to put increased pressure in areas where regulations are lax and water risk is high (e.g., India, China). Such considerations should be taken into account within the context of supplier management processes. We introduce a hierarchical framework, using Monte Carlo Analytic Hierarchy Process (MCAHP), to aggregate relevant indicators into an index score designed to assess suppliers' water risk based on their location. Our framework distinguishes between strategic sourcing decisions and tactical supplier management. Thus, it supports two applications of particular importance for managers: the top down identification of regional-level water-risk and variability, and the bottom up supplier management at a raw-material level. We illustrate the application of our framework with a case study conducted within a business unit of Procter \& Gamble (P\&G), the global consumer products company; examining 1066 direct suppliers in over 75 countries. Our strategic sourcing analysis identifies 340 suppliers with high water-risk and singles out 3 countries in critical condition; experiencing high water-risk in addition to precarious conditions for civilian access to water. Additionally, our bottom up analysis identifies a single supplier of a water-intensive raw material that is expected to become critical in the coming years; thus enabling targeted supplier management from a water-stewardship perspective.
\end{abstract}

\section{Introduction}

April 2016, Mumbai-India. Water scarcity in the Maharashtra province pushed civic bodies to interrupt water flows to industrial belts. Experts estimate that this decision had a negative effect on India's index of industrial production growth (IIPG) on the order of 40 to 50 basis points $(0.4-0.5 \%)$, with the manufacturing sector alone taking a hit of 50 to 75 basis points $(0.5-$ $0.75 \%$ ) (Sinhal, 2016). July 2016, Cochabamba-Bolivia. 159 out of the city's 300 industries experienced production interruptions due to a water shortage caused by droughts. 30 municipalities declared a state of emergency. The environment assessor of the regional industry chamber (Camara Departamental de Industria de Cochabamba) estimated that industrial production in the area decreased 15\% (Castro, 2016). March 2017, Arequipa-Peru. Floods and mudslides followed intense rains in the south of the country. Water quality in the area suffered; the abnormal murkiness of the fresh water supply made sanitation impossible. Thousands of people and dozens of industries lost regular access to clean water for weeks (Zanabria, 2017).

*Corresponding author: maxi.udenio@kuleuven.be 
Climate change has disrupted previously stable cycles of rain, snow, and storms, making the natural supply of fresh water unpredictable. The relative speed of the transition to such unstable global water conditions has surprised governments and companies alike (Schneider, 2016). Recent studies indicate that at least four billion people face severe water scarcity at least one month a year (Mekonnen and Hoekstra, 2016). As the above examples illustrate, industrial locationssharing water resources with civilian populations-are particularly sensitive; disruptions in the water flow can force production shutdowns. Infrastructure deficiency, regulations, and growth in water demand contribute to the fact that water is becoming a scarce resource in many regions around the world (OECD, 2011; Schyns et al., 2015). Moreover, this view of water as a scarce resource, and the subsequent competition for its use, is expected to increase in the future (Hoekstra, 2014; WEF, 2015). As a result, water scarcity has been identified as one of the top global risks to business today (WEF, 2017). From a research perspective, the issue of water-related topics in sustainability is predictably growing in popularity. As an example, we refer the reader to the recently published special volume of this journal, dedicated to water innovation issues (Wehn and Montalvo, 2018).

Formally, a region is said to be experiencing water scarcity when facing "an excess of water demand over available supply" (Steduto et al., 2012) and water stress when "using more than 20\% of their available resources" (Arnell, 1999). With respect to demand, water requirements increased at a rate more than double that of the population increase during the past century (Zabarenko, 2011). With respect to supply, water is a renewable resource, but its availability is limited. It is a finite resource; there is a limited amount of precipitation, and water has to run through the hydrologic cycle before becoming available again (Hoekstra, 2013; Schyns et al., 2015). Water, moreover, is a local resource distributed unequally around the globe; as are the quality of local regulatory frameworks and infrastructure.

Water is a key ingredient in the manufacturing operations of a large number of firms (Jones et al., 2014). Due to the growing number of water challenges, investors increasingly expect firms to assess their internal and external water risks and disclose their progress in annual public reports. Firms with significant water requirements have, in recent years, started to track their internal water use in production as well as during the use phase of their finished products. Such measurements enable firms to quantify the impact of their processes on water use (Hoekstra, 2016) or water scarcity (Pfister et al., 2017). Nevertheless, the number of firms reporting and using such data is still small. Based on the latest Carbon Disclosure Project (CDP) report: "while more than two-thirds of supplier respondents to the supply chain program saw climate change opportunities, only $36 \%$ of suppliers responding to CDP's water program identified water-related opportunities. And only $28 \%$ see any water risks to their business, which compares to three-quarters that see climate change risks." (CDP, 2017). Furthermore, the problem of assessing the impact of water usage in the upstream supply chain (i.e., a firm's suppliers, their suppliers, and so on) has not been addressed in the literature thus far. This is despite a significant portion of the total environmental impact of a firm often being attributed to processes upstream (Pelton et al., 2016). As transparency of suppliers gains importance for competitiveness, firms must extend their water-risk management methodologies towards their upstream partners.

In this paper, we develop a framework for water-risk screening in an upstream supply chain. We are inspired by the risk management literature (Sodhi et al., 2012) and its application to sustainability research (Giannakis and Papadopoulos, 2016). Furthermore, we position our study within the "green supplier selection" problem (Appolloni et al., 2014) by considering access to water as a location-level, multi-dimension, risk criteria.

We argue that, compared to other sustainability areas, three main factors make water risk management at a supply chain level a unique challenge going forward: (1) The local nature of water risk, implying that it must be measured at a micro level, thus at the level of individual manufacturing locations; (2) The rise of developing economies such as India and China as major manufacturing centers for the global economy (Friedman, 2005) and in particular, the proliferation of specialized, small-scale, suppliers in industrial belts of these economies located in high water-risk areas; and (3) The clear hierarchy between water destined for human consumption and industrial use, whereupon water flow to factories is expected to be interrupted as demand for sanitized water outstrips supply in a particular area.

We quantify water-risk by using a Monte Carlo Analytic Hierarchy Process (MCAHP) to aggregate a theory-based set of indicators into a water-risk index. Our index considers both physical (e.g., baseline water stress) as well as amplifying indicators (e.g., quality of governance and regulation) of a given region's water risk. Moreover, our framework explicitly distinguishes between 
strategic and tactical decision-making. At the higher level, it enables strategic sourcing decisions by assessing suppliers at a regional level (top down). At the lower level, it supports tactical supplier management; identifying critical raw materials followed by an assessment of individual suppliers (bottom up).

We illustrate the use of our framework through the analysis of upstream water risk on a single P\&G business unit. Starting from 1066 active suppliers, our strategic sourcing decision framework identifies 3 critical regions, which at the moment contain 14 suppliers (top down approach). Then, we use product-level water consumption data to identify the most water-intensive raw material of a business unit and quantify the water risk of each of its 4 suppliers. (bottom up approach.)

This paper contributes to the theory by explicitly linking the issue of water risk with the strategic sourcing and supplier management problems. By incorporating amplifying water risks our index is particularly aware of the situation in developing countries, where regulations are lax and pressure on local water sources is high. Moreover, from a managerial perspective, we contribute to the decision-making processes at strategic and tactical levels by developing a framework that is easy to implement and has large impact potential, which we illustrate through a case study.

\section{Related Literature}

Since our main contribution is the development of a water risk screening framework within the area of risk management/supplier selection, we structure the discussion of related literature as follows. In Section 2.1 we discuss the issue of supplier selection and management; the methodologies employed and the most relevant articles. Next, in Section 2.2, we survey the literature related to supply chain risk management and, in particular, the literature discussing explicit sustainabilityrelated risks. Finally, in Section 2.3 we identify the issue of water stewardship and its relevance to SCM.

We focus on the papers most relevant to our study. We refer the reader to Tang (2006) and Scholten and Fynes (2017) for in-depth reviews of supply chain risk, uncertainty, and their link to sustainability; Jaehn (2016) and Tang and Zhou (2012), for literature reviews on sustainable operations; Ho et al. (2010) and Chai et al. (2013) for reviews on decision-making techniques on supplier selection; and Appolloni et al. (2014) for a review of green procurement in the private sector.

\subsection{Supplier Selection and Supplier Management}

Supplier Selection (SS) and Supplier Management (SM) refer to the systematic decision making strategies behind choosing, monitoring, and developing suppliers.

The first step in any SS problem is to define a set of criteria with which to evaluate suppliers. These criteria vary, and can be quantitative (e.g., liquidity, revenue) as well as qualitative (e.g., social responsibility). Following this, several techniques are used to quantify the criteria and rank suppliers. In the field of decision making theory, the techniques typically applied in SS can be clustered into three main categories: Multicriteria Decision Making (MCDM), Mathematical Programming (MP), and Artificial Intelligence (AI). Chai et al. (2013) find that, of the 123 journal articles published on the topic between 2008 and 2013, the majority (62\%) used MCDM techniques, followed by MP (49\%), and AI $(29 \%)^{1}$. Analytic Hierarchy Process (AHP), a type of MCDM, is the single most common technique, appearing in $25 \%$ of all articles surveyed. Other popular techniques are Linear Programming (MP, 15\%), TOPSIS (MCDM, 15\%), and Analytic Network Process (MCDM, 12\%).

Sustainable supplier selection incorporates sustainability-derived criteria into the problem. For example, Hashemi et al. (2013) use AHP to present an integrated framework for green supplier selection. The authors integrate criteria such as resource consumption and pollution production into the SS problem and perform a case study in an automobile factory.

A natural extension of SS is Supplier Management (SM), where the scope is expanded to include monitoring and developing existing buyer-supplier relationships (Modi and Mabert, 2007; Ivens et al., 2013). Methodologically, the monitoring of suppliers follows the SS process (Ittner et al., 1999); the development of suppliers, however, is triggered by the evaluation of suppliers at either the selection or monitoring stage (Hahn et al., 1990). Given that firms usually deal with a

\footnotetext{
${ }^{1}$ Note that a number of papers use multiple techniques from multiple categories.
} 
large number of diverse suppliers, a common strategy is to identify the most important relationships to work on, i.e., key supplier management (Ivens et al., 2009). See van de Vijver et al. (2009) for a complete review of the literature on collaboration on buyer-supplier relationships.

As with SS, the extension of SM into sustainable SM corresponds to the inclusion of sustainability as a metric to monitor and develop the existing buyer-supplier relationships. Zimmer et al. (2015) review the state of the sustainable supplier management literature. They identify 143 articles, published between 1997 and 2014, related to sustainable SM. In line with the recent popularity of the field, $83 \%$ were published after 2010. However, the majority (81\%) focus on supplier selection, neglecting post-selection steps. In terms of techniques, their findings are in line with Chai et al. (2013). In their classification, however, Fuzzy Logic (AI) is the most popular technique (31\%) followed by AHP (19\%). They suggest that the reason behind the popularity of Fuzzy Logic is that it combines well with mathematical-analytical methods. In terms of the identification of performance criteria according to their sustainability dimension, economic, environmental, and societal criteria make up, respectively, $53 \%, 38 \%$, and $9 \%$ of the total. It is interesting to note that water-related criteria make up only $1.8 \%$ of the total. The authors remark on the surprisingly low appearance of water-related criteria, specially in light of renowned organizations explicitly recommending its integration in environmental analysis (UNEP, 2010; GRP, 2013). This suggests that even though there is consensus on the importance of water in sustainability matters, the link to business processes is stil underdeveloped. A potential cause for this is the long-term, stakeholder, view that is common in business sustainability definitions (Ahi and Searcy, 2013). In particular, the local nature of water-risk (which must be measured at a production-site level) is at odds with an "integrative" approach, aimed at analyzing the aggregate, global impact of firms' performance.

\subsection{Supply Chain Risk}

Globalization and the increase in length and complexity of supply chains brought about a myriad of advantages, but also increased exposure to uncertainty. As a result, supply chain risk management has emerged as a fast-growing research topic (Sodhi and Tang, 2012). Supply Chain Risk Management attempts to handle uncertain (and disruptive) events in a systematic way.

In their comprehensive review of researchers perspective for supply chain risk management, Sodhi et al. (2012) identify different ways in which the process of SCRM is typically implemented: identify, assess, mitigate, and communicate. Moreover, the authors identify a definition gap in SCRM research; aided by survey responses, they show that the scope and perceived objectives of SCRM vary, even among the community. Supply chain risks can be endogenous (i.e., caused by the internal SC structure) or exogenous (i.e., caused by external developments); and from the point of view of a firm operating within a SC, supply-side or demand-side. In terms of definition, views differ whether SCRM is related to supply-demand matching issues (inherently probabilistic), is related to operational issues, or even if it must include strategic aspects of supply chain management.

In recent years, interest has appeared on sustainability-related SC chain risks (Giannakis and Papadopoulos, 2016). Rather than focusing exclusively on potential SC disruptions, this community is interested in classifying and assessing the environmental and societal risks associated with SCM. A number of articles argue that any risk management methodology needs to incorporate sustainability-related risks (Cousins et al., 2004; Teuscher et al., 2006; Anderson, 2006; Anderson and Anderson, 2009). These authors, however, typically incorporate sustainability-related risks into the financially-based performance measurements common in SCRM. (As opposed to including sustainability itself as an explicit performance metric.)

Cousins et al. (2004) introduce a framework where environment-related supplier initiatives act as a feedback loop for the analysis of the exposure of firms to risks (in the natural environment as well as business surroundings). From a strategic perspective, they warn against the over-reliance on a single supplier that may have a negative impact on the environment, or that "may fall foul of environmental legislation, regulation or public opinion". They classify environment-related supplier initiatives according to the level of perceived losses (i.e., high or low financial, societal, or other losses) and the availability of advanced strategic purchasing resources within a firm. Firms facing a similar threat will react differently according to their level of resources, and vice-versa.

Anderson and Anderson (2009) argue for mitigation of sustainability risk management citing figures from the British Government (Stern, 2007): the cost of mitigating sustainability risks is estimated at approximately $1 \%$ of the world's GDP; a low percentage compared to the potential costs related to adverse impacts, estimated at between $5 \%$ and $20 \%$ of the world's GDP. While 
these figures were subsequently disputed (Weitzman, 2007), researchers broadly agree with the conclusion that sustainability actions can be justified on economic grounds (Tol et al., 2006).

Giannakis and Papadopoulos (2016) recognize a number of similarities and differences between sustainability SCRM and "typical" SCRM. Sustainability-related risks are often easy to identify and difficult to assess. In part, this is due to the difficulty in assigning a quantitative value to factors such as long-term decline of the environment or of a firms' reputation. Nevertheless, the authors suggest that many sustainability-related risks can be considered as precursors of commonly studied risks such as supply- or demand-side disruptions. This suggests that a framework for sustainability risk management can complement traditional SCRM. In fact, they argue, sustainability risk management should be part of an overall strategy for risk management.

\subsection{Water Footprinting and Stewardship}

Firms are aware of the water challenges of today and the future. KPMG (2012) report that "companies in all sectors need to prepare themselves for a world where raw materials may be in short supply and subject to price volatility including large price increases and increased disruption to supplies." Makower (2014) argues that water is, in the mind of consumers, governments, and firms alike, already associated with global risks and crises. Furthermore, the aforementioned report (KPMG, 2012) identifies water scarcity as one of the top ten sustainability "megaforces" that will impact every business in the coming decades.

In this section we survey the literature linking water usage and business sustainability. The literature can be roughly split into three main streams: the literature that quantifies actual water usage (water footprinting), the literature that includes water within LCA-type inventory and impact analysis (water LCA), and the literature that deals specifically with corporate decision-making based on water risks (water stewardship).

Water Footprinting (WF, Hoekstra et al. (2011)) started as a methodology to explicitly measure the impact of man-made processes on the availability of water. At its core, WF associates a volumetric use of water to a given process and a volumetric availability based upon the location of the process (Hoekstra et al., 2011). To quantify the effect of a given process on the environment, thus, WF uses the ratio of local demand to supply. In addition to using detailed, local-level water usage data, WF also distinguishes between blue, green, and grey water. Blue water is the water from a catchment (water body); green water is the runoff water from rain; and grey water is the volume of water required to assimilate the load of pollutants. WF as a methodology has been primarily used, in part due to the data requirements, to analyze specific processes and to develop case studies within relatively tight boundaries (see, e.g., Zeng et al., 2012; Skouteris et al., 2018; $\mathrm{Xu}$ et al., 2018).

LCA, on the other hand, does not rely on fine-grained water usage data and can thus be implemented based on aggregate-level datasets. Conceptually, the inventory activities of LCA are comparable to those of WF; a volumetric measurement of water used by a process or product. LCA, however, differs in two important aspects from the philosophy of WF. First, only blue water is considered in its measurement under the assumption that it is the main water source for industrial applications. Second, the proposed method to assess the local impact of a process is a water-scarcity weighted water footprint. LCA's adoption in the water-sustainability literature is therefore evident in studies with a more aggregate view, were detailed data is either impossible or impractical to source (see, e.g., Scherer and Pfister, 2016; Muñoz et al., 2010; Leão et al., 2018).

There are arguments defending both positions (Hoekstra, 2016; Pfister et al., 2017). WF proponents (Hoekstra, 2016) argue that the LCA methodology distorts the real problem by introducing an artificial index that is not suitable for comparison across processes/locations. Moreover, they also argue that conceptually the amount of water stress is irrelevant for measuring the sustainability of a process, i.e., as long as the demand of water in a certain location is lower than its supply, then the location is sustainable in terms of water use-irrespective of any other factors. On the other hand, Hoekstra argues that even though water is a local resource, the impact should also be considered globally. In SC thinking, this means that when two alternative processes exist, then under a global view, as long as it is sustainable, the process with smaller volumetric impact is preferred. Even if it means extracting water from a more scarce area. Hoekstra (2016) develops an example to illustrate the conceptual issues and inconsistencies behind the use of the water-scarcity weighted water footprint metric. LCA proponents (Pfister et al., 2017) retort that both methodologies have different aims and can thus benefit from synergies in the research of both 
approaches. In particular, Pfister et al. (2017) argues that LCA tries to account for environmental impacts, while WF tries to account for the water productivity of global fresh water as a limited resource. Conceptually, the argument boils down to (a) whether water use or water scarcity should be minimized, and (b) how to quantify and define the appropriate metrics.

Moreover, many firms have adopted the issue of water usage within corporate social responsibility/sustainability initiatives, under the moniker of water stewardship. The alliance for water stewardship defines it as "the use of water that is socially equitable, environmentally sustainable and economically beneficial, achieved through a stakeholder-inclusive process that involves site- and catchment-based actions" (Al et al., 2014). In a broader interpretation of the term, the World Wildlife Fund (2013) explicitly includes "value chain operations" within the scope of water stewardship. However, even as sustainability reporting is now expected from firms, and even as several guidelines targeting businesses are in place (e.g., the corporate water disclosure guidelines from the UN global compact (UN, 2017), and the water initiative of the carbon disclosure project; CDP (2017)), current practice is unstructured and highly variable.

Jones et al. (2014) conducted a study on the disclosure of water sustainability reports of the UK's "top twelve superbrands". The authors find that nine of the twelve firms post sustainability reports on their corporate websites, and that all of them include some metric for water stewardship. The actual reports, in terms of depth and breadth, however, vary significantly; from detailed disclosure of water-usage goals and the associated progress to simple mentions of ongoing collaborations with water-related NGOs. Despite the available literature on water footprinting and impact measurement (see above), none of the firms studied adopt a standardized water-risk measurement methodology. Instead, the more involved firms resort to running their own projects (e.g, Heinz' global water risk screening project) and metrics (e.g., Nestle combined water stress index). With regards to water stewardship as a supply-chain-wide effort, only agricultural-based processes were included in projects extending upstream the reporting firms.

\section{Supply Chain Water Risk Screening Framework}

We build upon the aforementioned literature in the following way. Our objective is to provide a framework based on sound theoretical underpinnings such that the problem of supplier selection/evaluation can be embedded within water-based sustainability initiatives (e.g., corporate water stewardship). We position our study within the supplier management literature.

From a practitioner's perspective, the greatest challenge impeding progress within the application of water stewardship in the upstream supply chain is the overall size and complexity of the problem. This is primarily due to the local nature of water risk; site-level data would be needed for a firm to screen its suppliers (or potential suppliers) based upon a water-risk metric. For a multinational firm, it is not uncommon to have multiple layers of upstream suppliers numbering in the thousands. Collecting and managing such data is, at best, extremely time consuming and costly; most often, no data is known beyond the approximate (i.e., province/state, or city-level) location of production facilities.

In terms of the water $\mathrm{WF} / \mathrm{LCA}$ perspective of measuring the impact of a process, we argue that different supply chain objectives require different data sources and aggregation. (WF is typically used to measure water-intensive natural resources (e.g., beef production), whereas LCA is more often used in process-intensive resources such as found in the chemical and manufacturing industries.) Furthermore, we also recognize the issue of data confidentiality and the willingness to share sensitive data among firms. To account for this, we propose two complementary approaches for supply chain water risk screening. A top down approach, using publicly available data, to inform strategic decision-making, and a bottom up approach, combining public data and volumetric water consumption at the product level, to inform tactical decision-making.

Figure 1 shows a schematic representation of the proposed framework. A firm can use the top down approach to identify the firms within its supply chain operating in high water-risk areas based on their geographical location. Thus, in terms of supplier management, resources can be directed to, for example, manage high-risk areas with a high density of suppliers, or to manage strategic suppliers located in high-risk areas. Moreover, through scenario analysis, locations with high-risk potential (based on climate change expectations) can be defined. This allows decision-makers to define regional sourcing strategies (i.e., do we source in Southeast China? etc). Using the bottom up approach, a firm uses water consumption data to identify key product categories, processes, and raw materials. Note that the framework is methodologically agnostic, i.e., both LCA and WF 


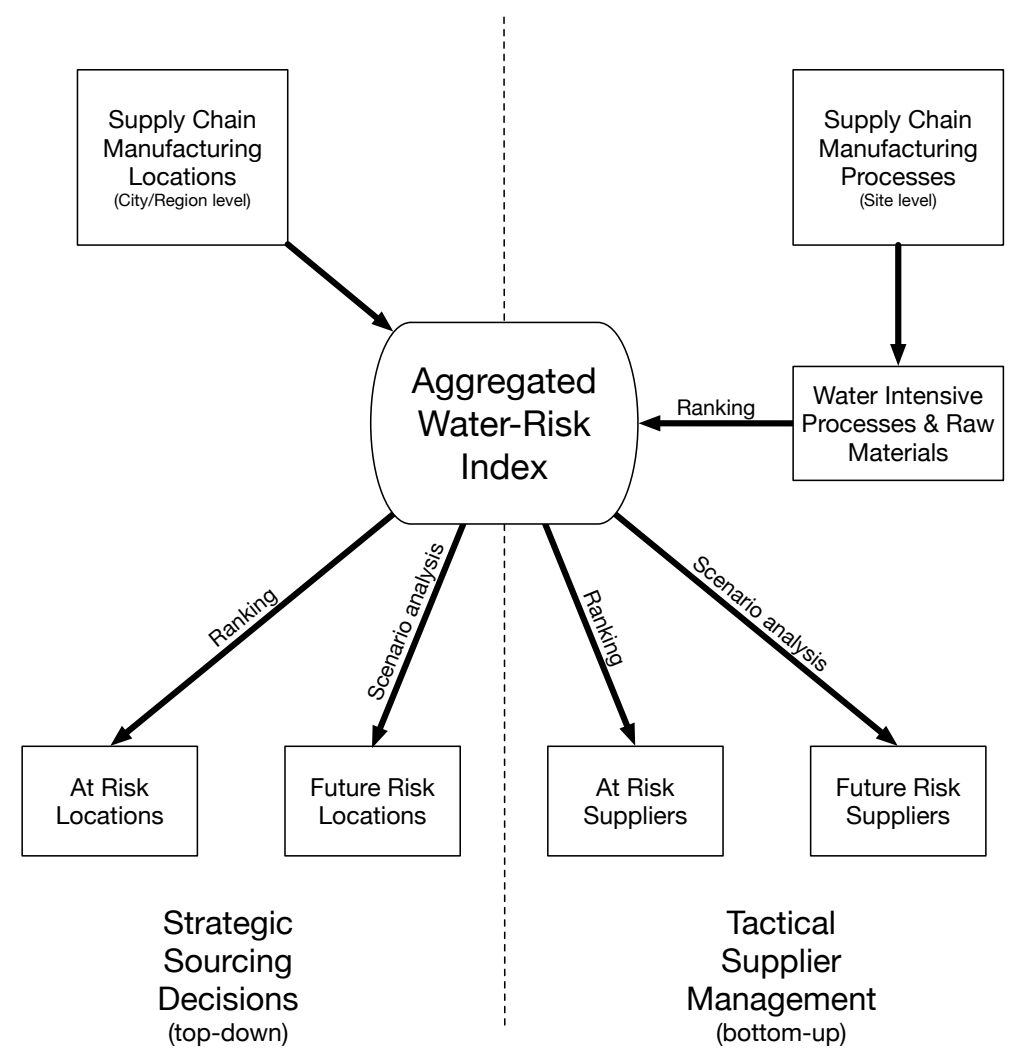

Figure 1: Our water-risk screening framework.

can be used to identify water intensive products and processes for a given application. Current and potential suppliers of these categories/processes/materials are then evaluated at the site level using the aggregated water risk indicator.

Central to both approaches is the aggregated supply chain water risk index. Starting from 6 publicly available water-related measures, we use an adapted Monte Carlo Analytic Hierarchy Process (MCAHP) to construct a single index. In line with technical and environmental reports (see e.g., Reig et al., 2013; Orr et al., 2011), we recognize different mechanisms behind water risk measurement. Specifically, we distinguish between the direct effect on risk due to physical measurements (such as the drought severity in a particular catchment), and the amplifying effect of regulatory and reputational measurements (such as the governmental enforcement of existing regulations).

\subsection{Relevant measures of water risk}

We distinguish between two main categories of water measures, physical and amplifying. For each, we select three indicators relevant to different aspects of water risk. Given the diverse nature of all these indicators, we normalize all indicators on a scale from 1 to 5 such that 1 is the minimum and 5 is the maximum risk derived from each metric.

\subsubsection{Physical water risks}

We quantify physical water risks through the indicators of water stress, seasonal variability, and drought severity. We obtain catchment-level data for these indicators from the World Resources Institute (WRI) Aqueduct Global Maps 2.1 dataset (Gassert et al., 2014).

1. Baseline Water Stress (BWS).

The Baseline Water Stress measures the ratio of total annual blue water withdrawal $(U t)$ divided by the average annual available blue water $\left(B_{a}\right)$ for the period 1950-2010. 


$$
r_{B W S}=\frac{U t_{2010}}{\text { mean }_{1950,2010}\left(B_{a}\right)}
$$

In contrast with other water stress indicators (e.g., Ground Water Stress), BWS explicitly considers the accessibility of water at a given location. This is particularly relevant in resource-rich countries that have significant amounts of water available, but that are not always accessible (e.g., Brazil).

2. Seasonal Variability (SV).

Seasonal Variability quantifies the natural variation in surface water supply while ignoring human influences (e.g. diversions and infrastructure). Specifically, it measures the ratio of the coefficient of variation of total blue water for each calendar month $\left(B T_{m}\right)$ and the overall mean monthly blue water.

$$
r_{s v}=\frac{s d_{j a n, \ldots, d e c}\left(\overline{B T_{m}}\right)}{\operatorname{mean}_{(j a n, \ldots, d e c)}\left(\overline{B t_{m}}\right)},
$$

with $\overline{B t_{m}}=\operatorname{mean}_{(1950,2010)}\left(B t_{i, m}\right), m \in j a n, \ldots$, dec.

SV explicitly accounts for destabilizing climate conditions that result in large uncertainty of the water supply.

3. Drought Severity (DS).

Drought Severity measures relative green water availability at a certain location over a period of time (Schyns et al., 2015). It focuses on regions where soil moisture deficits are longer and drier, which makes it difficult to adapt to and mitigate. A drought run is defined as a continuous period in which soil moisture remains below the 20th percentile of the monthly hydrograph $^{2}(q(\theta)<20 \%)$. The severity of drought run $i,\left(S_{i}\right)$, beginning at time $t_{0}$ is determined by the length of the drought $\left(D_{i}\right)$ multiplied by its intensity $\left(I_{i}\right)$. The length is measured in months, and the intensity in average number of points beneath the 20th percentile $(q(\theta))$. The drought severity indicator for a specific location is determined by:

$$
S=\sum_{t=t_{0}}^{D}\left(20 \%-q(\theta)_{t}\right)
$$

Following Gassert et al. (2014), we use the resampled mean drought severity data across the different hydrologic catchments,

$$
r_{\mathrm{DRO}, j}=\sum_{p \subset j} \operatorname{mean}(S)_{p}
$$

This indicator is aggregated over a historical period of time through measuring drought events from 1901 to 2008.

To quantify future scenarios, we follow Luck et al. (2015), who developed a robust model to project baseline water stress and seasonal variability for the next 10, 20 and 30 years. The model projects climate (i.e., supply) and socioeconomic variables (i.e., demand) to estimate the future water stress and variatbility. Climate variables include levels of temperature increase and constraint of emissions, whereas socioeconomic variables include population and GDP growth or level of urbanization. For the climate change variables, the authors assume relatively unconstrained emissions and a temperature increase of 2.6-4.8 degrees Celsius until 2100 (relative to 1986-2005 levels).

\subsubsection{Amplifying water risk}

In addition to the physical water risk indicators discussed thus far, we identified a number of additional country-level indicator to represent the amplification of water risk: External dependency; governance and regulation; and infrastructure. These amplifying indicators capture the influence

\footnotetext{
${ }^{2} \mathrm{~A}$ graph of the water level/rate of flow of a water catchment in relation to a function of time.
} 


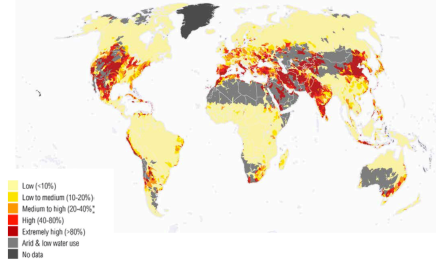

(a) Baseline Water Stress.

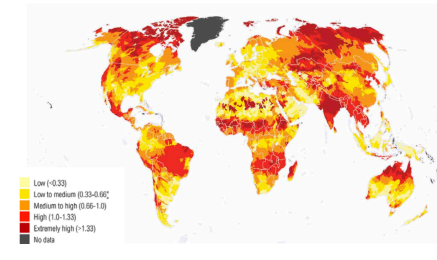

(b) Seasonal Variability.

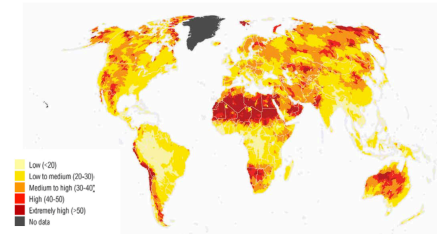

(c) Drought Severity.

Figure 2: Physical Water Risk Indicators (Source: WRI)

of the natural and political ecosystem as well as the regulatory environment, on the water risk faced by a given population. This follows from our line of reasoning that, in addition to the purely physical situation of water availability, these factors are -specially in a business environmentprofoundly relevant and must, thus, be represented in a water risk indicator.

1. External Dependency Ratio (EDR).

Water flows do not conform to political boundaries. Thus, there exist natural flows of water across countries. This can lead to situations where the water availability in a region depends on external conditions. The EDR indicator is based on the Dependency Ratio developed by the Food and Agriculture Organization of the United Nations (FAO), which measures the percentage of total renewable water resources (i.e., all surface and ground water inflows) originating from outside a country (OECD, 2016) and ranges between $0 \%$ and 100\%. To construct this indicator, we perform a linear normalization over a maximum threshold for critical dependency. Following Diop (2002) we use a percentage of $85 \%$ as the maximum threshold. While this is a good indicator on external dependency, it has the drawback of not considering outflows of water to other countries. Furthermore, this indicator does not take into account inflows of man-made origin, such as pipelines.

2. Governance and Regulation (GR).

Proficient governance is of importance for local water management. Local, state, or federal governments control how water is withdrawn and supplied to companies and the civilian population. Moreover, regulatory institutions define taxes and prices or request specific water quality standards from companies when water is discharged. We measure governance and regulation using the six Worldwide Governance Indicators (WGI) published by the World Bank since 1996 (Kaufmann et al., 2011). These indicators are based on three main signals of governance; the process by which governments are selected, monitored, and replaced; the capacity of governments to formulate effectively and implementation of sound policies; and the respect of citizens and the state for the institutions that govern economic and social interactions among them.

The intuition behind this metric is that each individual data source provides an imperfect signal of some deeper underlying notion of governance that is difficult to observe directly. This underlying notion suggests several smaller signals being used for different governance indicators.

Formally, we define this metric as the average of the six percentile rank values for each of the following indicators: Voice and accountability (VA), political stability and absence of violence and terrorism (PS), government effectiveness (GE), regulatory quality (RQ), rule of law (RoL), and control of corruption (CoC). Thus, the GR indicator captures relative ranks across all countries,

$$
\mathrm{GR}_{j}=1 / 6 \sum_{i=1}^{6}\left(1-g r_{i, j}\right)
$$

where $g r_{i, j}$ is the rank value $i$ (as defined above) for country $j$. (See Kaufmann et al. (2011) for a detailed discussion on each individual component of this indicator.)

3. Infrastructure (I).

Infrastructure is one of the biggest challenges facing the insecure supply of water. While 
Table 1: Summary of indicators

\begin{tabular}{lll}
\hline Indicator & Formula & Source \\
\hline Physical water risks & & \\
Baseline Water Stress & $r_{B W S}=\frac{U t_{2010}}{m e a n_{1950,2010}\left(B_{a}\right)}$ & Gassert et al. (2014) \\
Seasonal Variability & $r_{s v}=\frac{\operatorname{sd}_{j a n, \ldots, d e c}\left(\overline{B T_{m}}\right)}{\operatorname{mean}_{(j a n, \ldots, d e c)}\left(\overline{B t_{m}}\right)}$ & Gassert et al. (2014) \\
$\begin{array}{l}\text { Drought severity } \\
\text { Amplifying water risks }\end{array}$ & $S=\sum_{t=t_{0}}^{D}\left(20 \%-q(\theta)_{t}\right)$ & Gassert et al. (2014) \\
External dependency ratio & & OECD (2016) \\
Governance and regulation & $\mathrm{GR}_{j}=1 / 6 \sum_{i=1}^{6}\left(1-g r_{i, j}\right)$ & Kaufmann et al. (2011) \\
Infrastructure & $\mathrm{I}_{j}=\sum_{i=2000}^{2015}\left(1-a_{i, j}\right)$ & Diop (2002) \\
\hline
\end{tabular}

population continues to grow extensively, water infrastructure continues to deteriorate and enormous investments and maintenance need to be made to uphold the supply of water for the public and companies. The OECD estimates that by 2025 the biggest share of global infrastructure investments is on water infrastructure (OECD, 2011). The World Health Organization publishes an annual dataset to measure the access of public to an improved water source (WHO and Unicef, 2016). It refers to the percentage of population using an improved drinking water source within a given country (e.g. piped water, public taps or rainwater collection). To translate this to infrastructure development indication, we observe this indicator over a period of time. We consider the period of 2000-2015 and construct the indicator as the cumulative difference to $100 \%$ accessibility,

$$
\mathrm{I}_{j}=\sum_{i=2000}^{2015}\left(1-a_{i, j}\right),
$$

where $a_{i, j}$ is the access to water in year $i$ for country $j$.

Similar to the EDR indicator, we normalize with a critical threshold. In this case, this threshold is set at $65 \%$ of the civilian population having access to water (Diop, 2002). (This translates to a scaled value of 5 if a country provided over the last 15 years on average less than $65 \%$ of the public with access to water.)

After introducing the above indicators we conducted statistical analysis through the (Pearson) correlation which showed no noteworthy correlation.

\subsection{Constructing a water-risk index}

\subsubsection{Analytic Hierarchy Process and Monte Carlo Analytic Hierarchy Process}

In this section, we use Multiple Attribute Decision Making (MADM) methodologies to construct a single water-risk index based upon the physical and amplifying water risks presented in Section 3.1. In particular, we use an Analytic Hierarchy Process (AHP) approach and its simulation-based extension, Monte Carlo Analytic Hierarchy Process (MCAHP) to derive weights for each of the individual metrics from survey data obtained from expert judges.

The Analytic Hierarchy Process (AHP) methodology is broadly used as a preference theory in decision making. Of particular relevance for this study is its extensive use in Supply Chain decision making. (See, e.g., Ishizaka and Labib (2011) for and an application to supplier selection, and Momani and Ahmed (2011) for an application to the technology selection problem.) (ADD Zahedi (1986) and Wind and Saaty (1980)) AHP uses independent, judgemental, pairwise comparisons (made by one or more subject experts) among attributes to derive reciprocal comparison matrices. Provided that these matrices pass a validity test (i.e., the comparisons made by each individual are internally consistent), a single vector of weights can be computed from each matrix. If more than one expert provides comparisons, the geometric mean of all the weight vectors is used to aggregate all judgements into a single weight vector.

Let $A_{k}=\left[a_{k i j}\right]$ be a positive comparison matrix. Here, $a_{k i j}$ is the judgemental evaluation of expert $k \in\{1, \ldots, N\}$, comparing attributes $i \in\{1, \ldots, m\}$ and $j \in\{1, \ldots, m\}$. Following Saaty (1987), the elements of the matrix correspond to a discrete Saaty scale; $a_{k i j}=\{1, \ldots, 9\}$, where 1 indicates no difference on the importance of attribute $i$ over $j$, and 9 indicates the highest possible order of affirmation for the importance of $i$ over $j$. The reciprocal elements of a comparison matrix 
are computed such that $a_{k j i}=\{1 / 9,1 / 8, \ldots, 1 / 1\}$. The scale of weights of any given comparison matrix is given by solving for the principal eigenvector $\lambda$ of the matrix (Saaty, 2003).

The entries of $A_{k}$ need not be transitive. Thus, for a given expert $k$, comparisons $a_{k 12}>1$ and $a_{k 23}>1$ do not imply $a_{k 13}>1$. Such a matrix is said to be inconsistent. Formally, a matrix $A_{k}$ is inconsistent if $a_{k 12} a_{k 23} \neq a_{k 13}$. It can be shown that, if a positive reciprocal matrix of order $n$ is consistent, then its principal eigenvalue $\left(\lambda_{\max }\right)$ is equal to $n$. Moreover, when said matrix is inconsistent, then $\left(\lambda_{\max }\right)>n$ (Saaty, 1980; Harker, 1987). Thus, the difference between the principal eigenvalue of a given matrix and its order $n$ is a measure of its consistency. To evaluate the validity of a comparison matrix, we compute a consistency index $(C I)$ and a consistency ratio $(C R)$. Formally, let $C I_{k}$ be the consistency index of matrix $A_{k}, C I_{k}=\left(\lambda_{k, \max }-n_{k}\right) /\left(n_{k}-1\right)$, where $\lambda_{k, \max }$ is the principal eigenvalue of matrix $A_{k}$. The consistency ratio is defined as $C R_{k}=C I_{k} / R I$, with $R I$ the random matrix consistency index, defined as the average value of $C I$ for random matrices using the Saaty scale. A commonly used cutoff point for $C R$ is 0.1 . Comparison matrices with $C R_{k}<0.1$ are judged inconsistent, and therefore not used in determining the final weights (via the geometric mean of the individual weight vectors) (Ishizaka and Labib, 2011; Saaty, 1987).

MCAHP extends the AHP methodology by incorporating Monte Carlo simulation. Rather than computing the required weights directly from the comparison matrices, these are used to estimate a continuous distribution for each pairwise comparison. MCAHP, thus, addresses the uncertainty inherent in decision makers required to translate subjective judgements into a single point estimate (Ataei et al., 2013). In addition, MCAHP allows for statistical sensitivity analysis of the results (Banuelas and Antony, 2004; Vaidya and Kumar, 2006). MCAHP directly addresses the issue of a lack of probabilistic interpretation of the results of AHP. Therefore, using MCAHP allows us to compute a confidence interval for the resulting weights.

In this view, the pairwise comparisons $a_{i} j$ are random variables and the associated expert judgements $a_{k} i j$, realizations of said variables. To estimate the probability information of $a_{i} j$, we assume that the underlying distribution function is equal for every expert. To determine the distribution fit for each pairwise comparison, we extend the approach used in (Ataei et al., 2013). Instead of assuming an a priori distribution for the probability function of the indicators, we estimate the best-fit parameters for a number of distributions ${ }^{3}$ using maximum likelihood (check this). We then quantify the goodness of fit of the of each distributions through a KolmogorovSmirnov (KS) test and use the best fit for the Monte Carlo simulation. Appendix A shows a summary of the fitted distributions per indicator.

Simulation runs are then used to generate $M$ comparison matrices. The randomly generated, valid, comparison matrices are then used to estimate the final weights. As a final sanity check, the final weights are vetted by a group of external experts.

\subsubsection{Judgmental Comparisons and Resulting Indices}

Experts within and outside the company $(N=11)$ performed the pairwise comparisons for each of the physical and amplifying water risks. For the MCHAHP approach, we conducted 1000 replications of the Monte Carlo simulation runs; each run generating 10000 comparison matrices. The critical value of $D_{n}$ with a high significance level of $\alpha=0.2$ was 0.307 .

Table 2 details the weights computed from the responses and the resulting consistency ratio for each of the experts' responses. Table 3 shows the weights computed using the AHP and MCAHP approaches. To illustrate the robustness of the index, Table 4 shows the results of a single simulation run. In addition to the mean indicator weight, the table shows the number of times each indicator appears in a given ranking (we denote 1 for the indicator with the highest weight, 2 for the indicator with the second highest weight, and so on) for each of the consistent matrices generated by the simulation run. Finally, for an additional robustness check, we re-run the MCAHP approach following the methodology of Ataei et al. (2013), i.e., fitting a triangular distribution to each of the pairwise comparisons. The results are not significantly different.

The results show that physical risks are viewed as the essential component of decision making; accounting for more than $75 \%$ of the final aggregated index. It is interesting to note that the confidence bounds for the physical water risks are substantially tighter than for the amplifying risks. In terms of ranking, 10 out of the 11 experts ranked BWS as the top priority, and 8 out of 11 assessed the physical risks with the same ranking. For the amplifying risks, on the other hand, the individual judgements do not show a clear priority; every indicator was ranked first among

\footnotetext{
${ }^{3}$ Uniform, Triangular, LogLogistic, Beta, Pearson, Exponential, Lognormal, and Gamma.
} 
Table 2: Resulting indicator weights and consistency ratio for individual experts

\begin{tabular}{cccccccccccc}
\hline Expert: & 1 & 2 & 3 & 4 & 5 & 6 & 7 & 8 & 9 & 10 & 11 \\
\hline BWS & $39.6 \%$ & $47.9 \%$ & $49.3 \%$ & $43.5 \%$ & $44.8 \%$ & $32.0 \%$ & $51.0 \%$ & $45.7 \%$ & $29.3 \%$ & $29.9 \%$ & $45.0 \%$ \\
SV & $18.8 \%$ & $18.9 \%$ & $24.6 \%$ & $22.2 \%$ & $22.6 \%$ & $22.8 \%$ & $20.24 \%$ & $24.8 \%$ & $6.6 \%$ & $42.8 \%$ & $17.8 \%$ \\
DS & $4.9 \%$ & $13.6 \%$ & $14.9 \%$ & $9.9 \%$ & $12.7 \%$ & $2.7 \%$ & $14.6 \%$ & $6.8 \%$ & $21.5 \%$ & $6.6 \%$ & $24.7 \%$ \\
EDR & $6.9 \%$ & $4.0 \%$ & $3.3 \%$ & $9.6 \%$ & $12.0 \%$ & $23.0 \%$ & $3.8 \%$ & $6.7 \%$ & $18.1 \%$ & $10.4 \%$ & $3.5 \%$ \\
GR & $13.5 \%$ & $11.3 \%$ & $3.5 \%$ & $5.5 \%$ & $4.7 \%$ & $8.2 \%$ & $4.6 \%$ & $3.6 \%$ & $8.3 \%$ & $5.7 \%$ & $2.5 \%$ \\
I & $16.2 \%$ & $4.3 \%$ & $4.5 \%$ & $9.4 \%$ & $3.3 \%$ & $11.4 \%$ & $5.7 \%$ & $12.4 \%$ & $16.3 \%$ & $5.7 \%$ & $6.4 \%$ \\
\hline CR & 0.10 & 0.08 & 0.10 & 0.37 & 0.05 & 0.52 & 0.09 & 0.07 & 0.09 & 0.03 & 0.11 \\
\hline
\end{tabular}

Table 3: Resulting indicator weights

\begin{tabular}{lcccc}
\hline \multirow{2}{*}{ Indicator } & \multicolumn{2}{c}{ AHP } & \multicolumn{2}{c}{ MCAHP } \\
& Mean & StdDev & Mean & StdDev \\
\hline BWS & $44.90 \%$ & $8.0 \%$ & $44.28 \%$ & $5.13 \%$ \\
SV & $22.0 \%$ & $8.5 \%$ & $22.97 \%$ & $4.72 \%$ \\
DS & $11.1 \%$ & $6.8 \%$ & $11.64 \%$ & $3.68 \%$ \\
EDR & $8.2 \%$ & $6.4 \%$ & $8.30 \%$ & $2.91 \%$ \\
GR & $7.2 \%$ & $3.5 \%$ & $6.25 \%$ & $2.07 \%$ \\
I & $6.6 \%$ & $4.8 \%$ & $6.56 \%$ & $2.23 \%$ \\
Number of consistent matrices (mean/median) & $1095.33 / 1100.5$ \\
Consistency index & \multicolumn{3}{c}{0.06} \\
\hline
\end{tabular}

amplifying factors by at least one expert. This is reflected in the final indicator as well as in the simulation results. In terms of ranking, the simulation shows that all amplifying factors are ranked significantly lower than physical indicators, but no clear hierarchy can be drawn among them. We see that at the $5 \%$ confidence level we cannot reject the hypothesis that all amplifying factors are considered to have the same impact. The lack of consensus regarding amplifying factors suggests that even among experts, much more ambiguity exists about the impact and importance of these factors. More research may be needed to establish more quantitative and better validated measures for these amplifying impacts.

\section{Application of the Framework to P\&G's Supplier Network}

In this section, we apply our water-risk screening framework to the network of suppliers associated with one of P\&G 's business units. With support of the functional departments Purchasing, Research \& Development, and Sustainability, we constructed a database of tier-1 suppliers (i.e., direct suppliers). At the moment of analysis (August 2016), the database consisted of 1066 active and 1403 inactive (previously, but not currently used) suppliers in 75 countries — supplying a combined

Table 4: Average values and indicator ranking for a representative simulation run.

\begin{tabular}{lllllll}
\hline Ranking & BWS & SV & DS & EDR & GR & I \\
\hline 1 & 1131 & 18 & - & - & - & - \\
2 & 18 & 1041 & 83 & 5 & 2 & - \\
3 & - & 82 & 716 & 237 & 40 & 74 \\
4 & - & 7 & 228 & 434 & 236 & 244 \\
5 & - & 1 & 85 & 286 & 364 & 413 \\
6 & - & - & 37 & 187 & 507 & 418 \\
\hline Mean weight & $44.20 \%$ & $22.95 \%$ & $11.87 \%$ & $8.22 \%$ & $6.27 \%$ & $6.49 \%$ \\
\hline
\end{tabular}


1017 different raw materials. The geographical distribution is as follows; $41.2 \%$ were located in the Middle East and Europe (EMEA), 30.2\% in North America (NA), 20.\% in Asia, and 7.7\% in Latin America (LA).

To inform strategic sourcing decisions, we start from the top down. Using plant location data as an input, our framework identified 5 at-risk supplier regions. For tactical supplier management, we start from the bottom up. First, we quantify the water use of individual product families at all stages of their lifecycle. Then, focusing on the product family with highest water requirements for raw material production, we identify the most water-intensive raw material and the relevant suppliers. With this process, our framework identified 6 at-risk individual suppliers.

\subsection{Strategic Sourcing Decisions}

In this section, we show the results of applying the (top down) framework on the sample of 1066 active suppliers to identify supplier locations experiencing the highest water risk.

Figure 3 shows the results at the aggregate level, using a water-risk index value of 2.55 (corresponding to the 75th percentile of the sample) as the cutoff point between high and moderate-low water risk. Figure 3 a was constructed using the values updated at the moment of analysis, whereas Figure 3b incorporates water stress projections for the year 2040 (Luck et al., 2015).

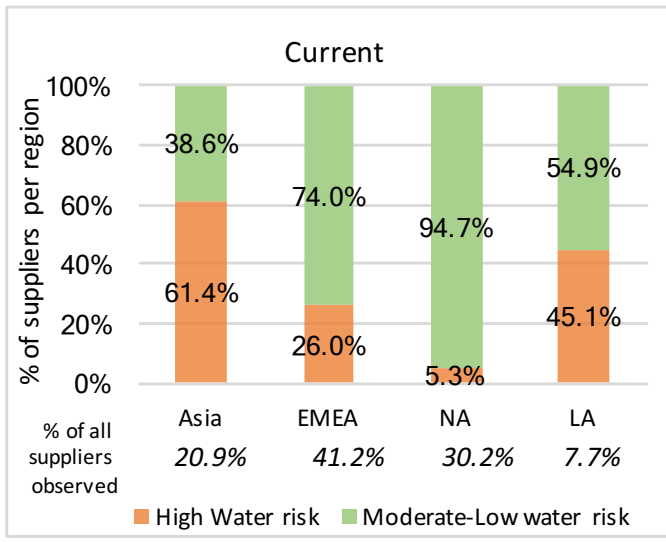

(a) Current water risk per region.

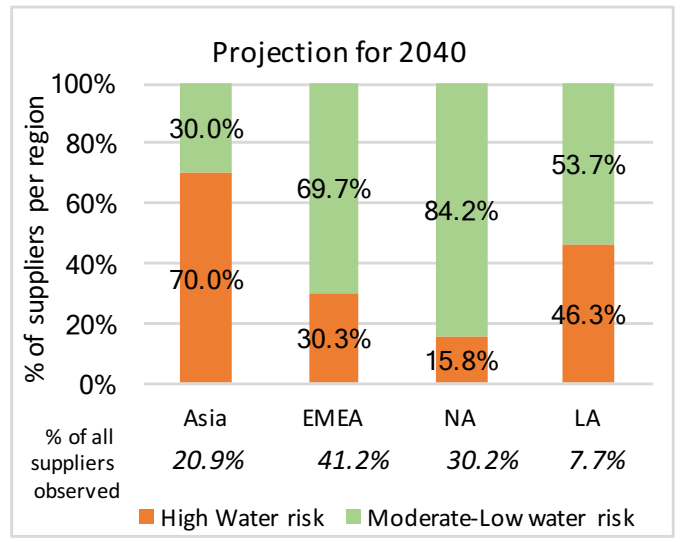

(b) Expected water risk per region.

Figure 3: Water risk

Overall, 305 suppliers $(\sim 29 \%)$ are located in high-risk areas. Asian suppliers face the highest water risk, followed by LA, EMEA, and NA. With the inclusion of the future water stress projection, the percentage of suppliers in high-risk areas is expected to increase across all four regions. The number of suppliers at future-risk locations rises to $378(\sim 35.5 \%)$. It's interesting to note that North America, while being the region with the lowest current relative number of at-risk locations, is expected to experience the largest increase in absolute terms. Figure 4 shows all supplier locations and their corresponding (current) water risk index. North and west India, as well as Northeastern China display the highest concentration of suppliers at critical water-risk levels. In North America, California, the Midwest, and Mexico appear to concentrate suppliers with high-water risk.

\subsubsection{Incorporating access to water}

The analysis shown thus far allowed us to identify geographic regions with high concentration of at-risk suppliers. From a managerial perspective, this allowed the company to short-list and prioritize current suppliers for further development. Moreover, from a strategic perspective, future sourcing decisions can incorporate the regional-level results.

P\&G's sustainability goals, however, incorporate social responsibility in addition to environmental sustainability as advocated by Sustainable Development Goal 6 (SDG6, UN, 2017). Therefore, to further understand the social responsibility aspect of the identified suppliers, we also quantify civilian access to sanitized water at a regional level.

To do so, we incorporate the improved water source and sanitation (access to water) indicator to our analysis (WHO and Unicef, 2016). Figure 5 shows all material suppliers grouped by country. The $\mathrm{x}$-axis indicates the water-risk index. The y-axis indicates the percentage of each countries' 


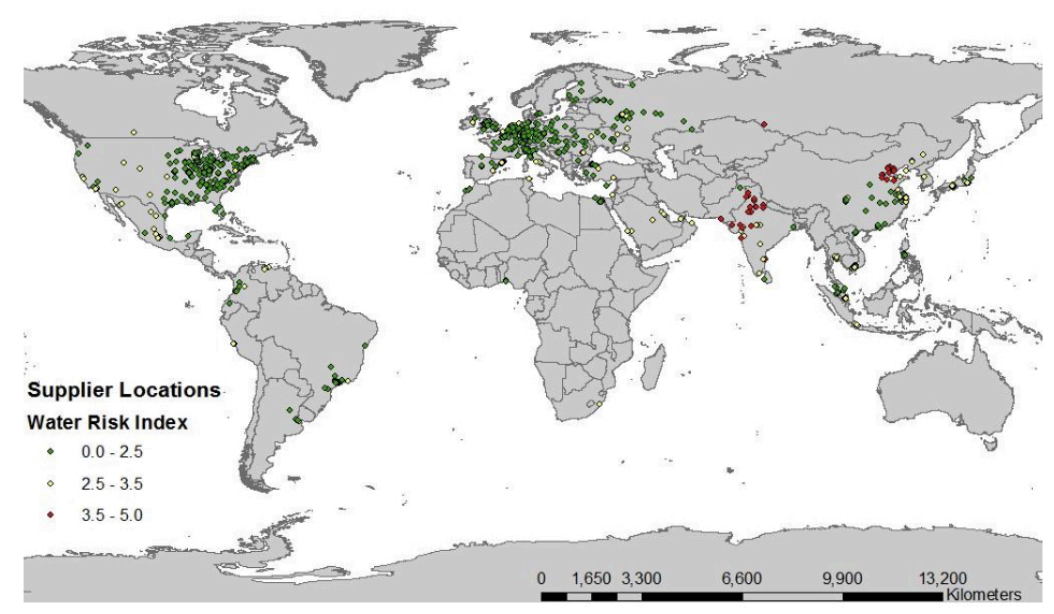

Figure 4: Water risk analysis of individual supplier locations.

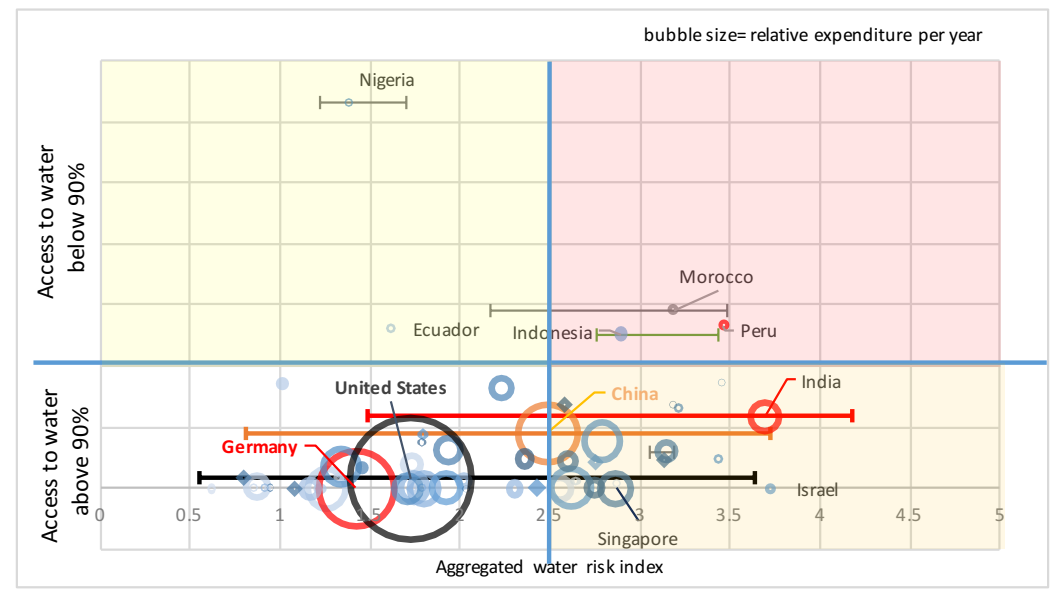

Figure 5: Water risk analysis for strategic sourcing decisions.

population with access to clean water. The thresholds for water risk (2.55) and access to clean water ( $90 \%$ of the population) are indicated with solid blue lines, dividing the plot into quadrants. The size of each circle indicates the total annual spend on suppliers located within the country, and the error bars show the range of aggregated water risk index scores of the suppliers within each country.

Suppliers of most immediate concern are located in the upper right quadrant (red zone). These represent suppliers located in regions of high-very high water risk, operating in countries where less than $90 \%$ of its people have access to clean water and sanitation sources. Suppliers based in Peru, Indonesia, and Morocco lay within this high risk quadrant. In total, 14 suppliers $(\sim 1.3 \%$ of the total) are singled out.

In addition to the identification of these critical suppliers, the results show a significant variability of water-risk per country. In a large number of cases, the scores show that low-risk and high-risk areas coexist within a single country (e.g. India, China, and U.S). This further emphasizes the need for site-level measurement of water-risk due to the local nature of water issues. 


\subsection{Tactical Supplier Management}

In this section, we show the results of applying the (bottom up) framework to identify at-risk suppliers based upon the water usage of the production process of the raw materials.

\subsubsection{Identifying water-intensive raw materials}

Given the characteristics of the processes under study, we use a public LCA-based database (Ecoinvent V3) to quantify the water use at each stage of the lifecycle of individual product families. In particular, we assessed the water usage of all processes per product family (including intermediate and raw material production) to identify the most water-intensive families. Note that the choice of LCA methodology results in a decision based upon average values of water consumption, thus the results are used as a high-level estimate to compare product families. From this analysis, we single out the product family with the highest non-cooling water. Finally, we identify the raw material with the highest contribution to its water use.

In this case study, the raw material itself is water intensive. This particular raw material comes in three different types, Type A, Type B, and Type C-the types differ in their characteristics. Currently, the company sources from 4 active suppliers ( 2 additional inactive suppliers exist in the database). Figure 6 shows the relative water usage (in $m^{3}$ per metric ton of raw material) for each type in the $\mathrm{y}$-axis, the aggregated water risk index for each supplier in the $\mathrm{x}$-axis, and the yearly purchases of each raw material (in metric tons) quantified with the size of each bubble ${ }^{4}$. Moreover, the expected future water-risk index (for 2040) for each supplier is indicated with a dotted bubble.

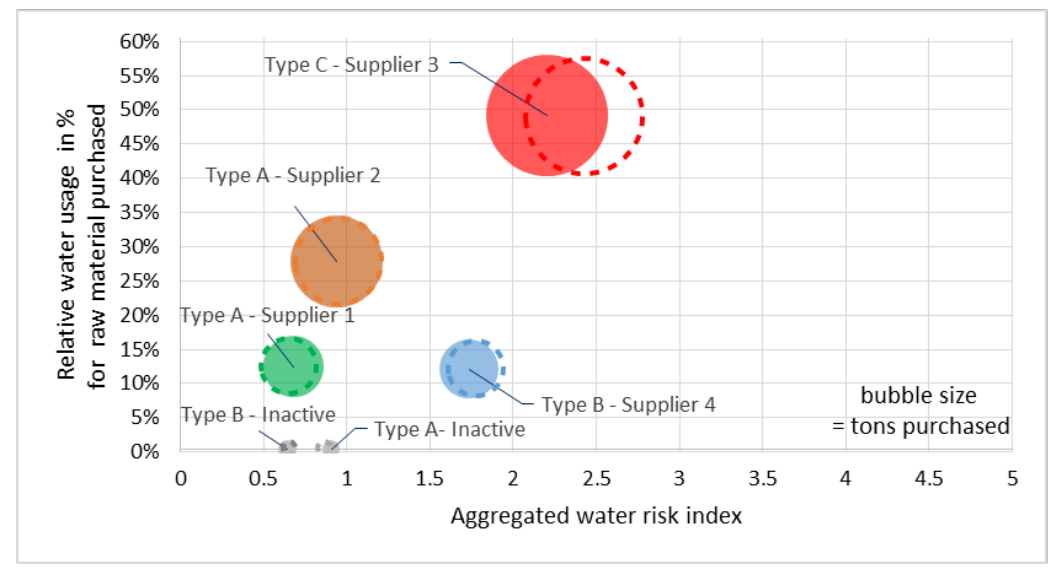

Figure 6: Water risk analysis for tactical supplier management.

The results show that all the supplier locations are currently below the threshold set in the previous section to identify high water-risk. Note, however that supplier 3 is the only source of Type $\mathrm{C}$ and (a) has the highest water-risk index, (b) is the largest of the suppliers in terms of sales to $\mathrm{P} \& \mathrm{G}$, and (c) its water-risk level is expected to increase significantly in the coming years. Thus, the results suggest that $P \& G$ engage with supplier 3 to further investigate the root causes of the current water risk and actively manage their processes in light of the expectations of increase in water risk in the coming decades.

\section{Discussion}

Building on extant research on supply chain sustainability, this study identifies water as an important driver of firm-level decision-making. In particular, we highlight the importance of using water-related risks to support decision-making at a strategic and tactical levels. We examine the role of physical and amplifying measures of water-risk. With the input of a panel of experts, we use a MCAHP methodology to aggregate existing indicators into a comprehensive index aimed at quantifying the water-risk of a given firm. We find consensus on the relative importance of physical risks over amplifying risks, however, the somewhat qualitative, second order, effect of the

\footnotetext{
${ }^{4}$ The water use data was collected from the suppliers and was complemented by the water background flow data from LCA databases to account for water usage upstream of the raw material suppliers.
} 
latter results in a less robust ranking for amplifying effects. We illustrate the application of our framework on data collected within one P\&G business unit. We find that approximately $300(30 \%)$ active suppliers are located in what we consider to be high-risk areas. This number is expected to increase in the coming decades. Prioritizing the social aspects of water scarcity, we are able to pinpoint $14(1.3 \%)$ high priority suppliers. Moreover, using company-specific and public volumetric data, we identify the most critical raw materials in terms of water usage, and quantify the present and expected water-risk of its 4 active suppliers.

Our study contributes to the literature by providing a framework to measure dimensions of water-risk that are particularly relevant for supply chain management decisions. This framework recognizes that supplier management requires different data at different aggregation levels. As such, we advocate for the use of location-specific data to inform strategic sourcing decisions, and a combination of this data with site-level and product-level volumetric water usage data to inform tactical supplier management decisions. From the perspective of the company, the development of a multiple-indicator water risk methodology for use in the assessment of water risk at supplier locations helped provide a strategic, data-based approach to prioritize suppliers with respect to water stewardship interventions. The top down application enabled an efficient yet robust method to screen over 1000 suppliers to reach a short-list prioritized for further engagement and investigation. Any organization that knows the location of their supplier manufacturing facilities can quickly determine which suppliers they should engage with first. The results are immediately actionable and enable a data-based conversation to occur with the high risk suppliers. In addition, the methodology incorporates both environmental and social aspects of water risk, as encouraged by SDG 6. The bottom up approach on a water-intense raw material group combined the results of the aggregated water risk index with water usage to better understand risk of an important raw material; this enables tactical supplier management explicitly targeted towards boosting the firms' water stewardship. While it is more challenging to obtain accurate water usage volumes from suppliers, the incorporation of this usage data is essential to more holistically assess risk at a supplier location. Without fully understanding how water is used at a facility, it is difficult to accurately assess risk. There may be instances when a facility is located in a high water risk region, but does not use water. When water usage data is not available, it is recommended to use the top down application of the methodology and to engage with the high risk sites to learn more about their water usage. This methodology can be used by companies to assess and act on risks related to water in their supply chain. Using best available data and country-level, or sub-national metrics when available, it is possible to prioritize suppliers and supplier sites for further investigation and intervention. By better understanding both the environmental and social water risk, companies will be more prepared for maintaining an efficient and effective business while being good stewards of the water they are associated with throughout the life cycle of their products and services.

\section{Acknowledgments}

The authors would like to express their gratitude to the Editor and two anonymous referees for constructive feedback that helped increase the quality of our work. We would also like to thank the 11 internal and external experts that have provided their input over the course of this study. Furthermore, we would like to thank Sergio Barbarino, Andy Butler, and Gert van Hoof at P\&G, and the WRI Aqueduct program team for continuously sharing their guidance and suggestions to improve our water risk framework. 


\section{Appendix A: Distribution fitting of pairwise comparison arrays}

\begin{tabular}{c|c|c|c|c}
\hline $\begin{array}{c}\text { Pairwise } \\
\text { comparison }\end{array}$ & $\begin{array}{c}\text { Fitted } \\
\text { Distribution }\end{array}$ & Bounds* & $\boldsymbol{D}_{\boldsymbol{n}}$ & $\begin{array}{c}\text { Best unbound/bound } \\
\text { distribution } \\
\text { value) }\end{array}$ \\
\hline BWS-S
\end{tabular}

Figure 7: Overview of distribution fitting.

* Italics represent bounds that are fixed to a specific value $(1 / 9$ or 9$)$.

** underlined distributions are the best bound distributions in comparison to the unbound distributions.

\section{References}

Ahi, P. and Searcy, C. (2013). A comparative literature analysis of definitions for green and sustainable supply chain management. Journal of Cleaner Production, 52:329-341.

Al, I. A., Ahmad, S., Ballestero, M., Bezbaroa, S., Cookey, P., Dourojeanni, A., Galli, C., Langford, J., Mensink, M., Opondo, G., Park, J. M., Pinero, E., Ruffier, P., Witmer, L., and Xin, H. (2014). The aws international water stewardship standard. Technical Report http://a4ws.org/wpcontent/uploads/2017/04/AWS-Standard-Full-v-1.0-English.pdf, International Standard Development Committee (ISDC).

Anderson, D. R. (2006). The critical importance of sustainability risk management. Risk Management.

Anderson, D. R. and Anderson, K. E. (2009). Sustainability Risk Management. Risk Management and Insurance Review, 12(1):25-38.

Appolloni, A., Sun, H., Jia, F., and Li, X. (2014). Green Procurement in the private sector: a state of the art review between 1996 and 2013. Journal of Cleaner Production.

Arnell, N. W. (1999). Climate change and global water resources. Global environmental change, 9:S31-S49. 
Ataei, M., Shahsavany, H., and Mikaeil, R. (2013). Monte carlo analytic hierarchy process (mahp) approach to selection of optimum mining method. International Journal of Mining Science and Technology, 23(4):573-578.

Banuelas, R. and Antony, J. (2004). Modified analytic hierarchy process to incorporate uncertainty and managerial aspects. International Journal of Production Research, 42(18):3851-3872.

Castro, T. (2016). Escasez de agua afecta a más de la mitad de industrias de la llajta. Opinion Cochabamba, http://www.anesapa.org/noticias/opinion-22-de-julio-de-2016-escasez-deagua-afecta-a-mas-de-la-mitad-de-industrias-de-la-llajta/(Last Accessed: 30/12/2017).

CDP (2017). Missing link: Harnessing the power of purchasing for a sustainable future. Technical report, Carbon Disclosure Project.

Chai, J., Liu, J. N. K., and Ngai, E. W. T. (2013). Application of decision-making techniques in supplier selection: A systematic review of literature. Expert Systems With Applications, 40(10):3872-3885.

Cousins, P. D., Lamming, R. C., and Bowen, F. (2004). The role of risk in environment-related supplier initiatives. International Journal of Operations \& Production Management, 24(6):554565 .

Diop, S. (2002). Vital water graphics: an overview of the state of the world's fresh and marine waters, volume 1. UNEP/Earthprint.

Friedman, T. L. (2005). The world is flat: A brief history of the twenty-first century. Macmillan.

Gassert, F., Luck, M., Landis, M., Reig, P., and Shiao, T. (2014). Aqueduct global maps 2.1: Constructing decision-relevant global water risk indicators. Washington, DC: World Resources Institute. http://www. wri. org/sites/default/files/Aqueduct_Global_Maps_2.

Giannakis, M. and Papadopoulos, T. (2016). Supply chain sustainability: A risk management approach. International Journal of Production Economics.

GRP (2013). G4 sustainability reporting guidelines. reporting principles and standard disclosures. Global Reporting Initiative., Retrieved from https://www.globalreporting.org/resourcelibrary/GRIG4-Part1-Reporting-Principles-and-Stan dard-Disclosures.pdf.

Hahn, C. K., Watts, C. A., and Kim, K. Y. (1990). The supplier development program: A conceptual model. Journal of Purchasing and Materials Management, 26(2):2-7.

Harker, P. T. (1987). Derivatives of the perron root of a positive reciprocal matrix: with application to the analytic hierarchy process. Applied Mathematics and Computation, 22(2-3):217-232.

Hashemi, S. H., Karimi, A., Aghakhani, N., and Kalantar, P. (2013). A grey-based carbon management model for green supplier selection. In Grey Systems and Intelligent Services, 2013 IEEE International Conference on, pages 402-405. IEEE.

Ho, W., Xu, X., and Dey, P. K. (2010). Multi-criteria decision making approaches for supplier evaluation and selection: A literature review. European Journal of Operational Research, 202(1):1624 .

Hoekstra, A. Y. (2013). The water footprint of modern consumer society. Routledge.

Hoekstra, A. Y. (2014). Water scarcity challenges to business. Nature Clim. Change, 4(5):318-320.

Hoekstra, A. Y. (2016). A critique on the water-scarcity weighted water footprint in lca. Ecological indicators, 66:564-573.

Hoekstra, A. Y., Chapagain, A. K., and Aldaya, M. M. (2011). The water footprint assessment manual.

Ishizaka, A. and Labib, A. (2011). Review of the main developments in the analytic hierarchy process. Expert systems with applications, 38(11):14336-14345. 
Ittner, C. D., Larcker, D. F., Nagar, V., and Rajan, M. V. (1999). Supplier selection, monitoring practices, and firm performance. Journal of Accounting and Public Policy, 18(3):253-281.

Ivens, B. S., Pardo, C., Salle, R., and Cova, B. (2009). Relationship keyness: The underlying concept for different forms of key relationship management. Industrial Marketing Management, $38(5): 513-519$.

Ivens, B. S., van de Vijver, M., and Vos, B. (2013). Managing and developing key supplier relationships: An introduction to the special issue, discussion and implications. Industrial Marketing Management, 42(2):135-138.

Jaehn, F. (2016). Sustainable operations. European Journal of Operational Research.

Jones, P., Comfort, D., and Hillier, D. (2014). Water Stewardship and Corporate Sustainability. Economia Seria Management.

Kaufmann, D., Kraay, A., and Mastruzzi, M. (2011). The worldwide governance indicators: methodology and analytical issues. Hague Journal on the Rule of Law, 3(2):220-246.

KPMG (2012). Expect the unexpected: Building business value in a changing world. https://www.kpmg.de/docs/expect-unexpected.pdf(Last Accessed: 30/12/2017).

Leão, S., Roux, P., Núñez, M., Loiseau, E., Junqua, G., Sferratore, A., Penru, Y., and Rosenbaum, R. K. (2018). A worldwide-regionalised water supply mix (wsmix) for life cycle inventory of water use. Journal of Cleaner Production, 172:302-313.

Luck, M., Landis, M., and Gassert, F. (2015). Aqueduct water stress projections: Decadal projections of water supply and demand using cmip5 gcms. Technical Note. Washington, DC: World Resources Institute. Available online at: http://www. wri. org/publication/aqueduct-waterstressprojections.

Makower, J. (2014). State of green business 2014.

Mekonnen, M. M. and Hoekstra, A. Y. (2016). Four billion people facing severe water scarcity. Science advances.

Modi, S. B. and Mabert, V. A. (2007). Supplier development: Improving supplier performance through knowledge transfer. Journal of Operations Management, 25(1):42-64.

Momani, A. M. and Ahmed, A. A. (2011). Material handling equipment selection using hybrid monte carlo simulation and analytic hierarchy process. World Academy of Science, Engineering and Technology, 59:953-958.

Muñoz, I., Milà-i Canals, L., and Fernández-Alba, A. R. (2010). Life cycle assessment of water supply plans in mediterranean spain. Journal of Industrial Ecology, 14(6):902-918.

OECD (2011). Oecd studies on water, meeting the challenge of financing water and sanitation: Tools and approaches. Technical report, OECD.

OECD (2016). Aquastat main database. Technical report, Food and Agriculture Organization of the United Nations.

Orr, S., Sanchez-Navarro, R., Schmidt, G., Seiz-Puyuelo, R., Smith, K., and Verberne, J. (2011). Assessing water risk. a practical approach for financial institutions. Technical report, World Wildlife Foundation.

Pelton, R., Li, M., and Smith, T. M. (2016). Optimizing eco-efficiency across the procurement portfolio. Environmental science and Technology.

Pfister, S., Boulay, A.-M., Berger, M., Hadjikakou, M., Motoshita, M., Hess, T., Ridoutt, B., Weinzettel, J., Scherer, L., Döll, P., et al. (2017). Understanding the lca and iso water footprint: A response to hoekstra (2016)"a critique on the water-scarcity weighted water footprint in lca". Ecological Indicators, 72:352-359. 
Reig, P., Shiao, T., and Gassert, F. (2013). Aqueduct water risk framework. Technical report, Working Paper. Washington, DC: World Resources Institute. Available online at http://www. wri. org/publication/aqueduct-water-risk-framework.

Saaty, R. W. (1987). The analytic hierarchy process - what it is and how it is used. Mathematical modelling, 9(3-5):161-176.

Saaty, T. L. (1980). The analytic hierarchy process: planning. Priority Setting. Resource Allocation, MacGraw-Hill, New York International Book Company, page 287.

Saaty, T. L. (2003). Decision-making with the ahp: Why is the principal eigenvector necessary. European journal of operational research, 145(1):85-91.

Scherer, L. and Pfister, S. (2016). Global water footprint assessment of hydropower. Renewable Energy, 99:711-720.

Schneider, K. (2016). Understanding water risks drives global investors.

Scholten, K. and Fynes, B. (2017). Risk and uncertainty management for sustainable supply chains. Springer.

Schyns, J. F., Hoekstra, A. Y., and Booij, M. J. (2015). Review and classification of indicators of green water availability and scarcity. Hydrology and Earth System Sciences, 19(11):4581.

Sinhal, P. (2016). Water shortage to affect industrial output: Experts. The Times of India, https://timesofindia.indiatimes.com/business/india-business/Water-shortage-to-affectindustrial-output-Experts/articleshow/51818065.cms(Last Accessed: 30/12/2017).

Skouteris, G., Ouki, S., Foo, D., Saroj, D., Altini, M., Melidis, P., Cowley, B., Ells, G., Palmer, S., and O'Dell, S. (2018). Water footprint and water pinch analysis techniques for sustainable water management in the brick-manufacturing industry. Journal of Cleaner Production, 172:786-794.

Sodhi, M., Son, B. G., and Tang, C. S. (2012). Researchers' perspectives on supply chain risk management. Production and Operations Management.

Sodhi, M. and Tang, C. S. (2012). Managing supply chain risk.

Steduto, P., Faurès, J., Hoogeveen, J., and Winpenny, J. (2012). Coping with water scarcity: an action framework for agriculture and food security. FAO Water Reports 38, Food and Agriculture Organization of the United Nations.

Stern, N. H. (2007). The economics of climate change: the Stern review. cambridge University press.

Tang, C. S. (2006). Perspectives in supply chain risk management. International Journal of Production Economics, 103(2):451-488.

Tang, C. S. and Zhou, S. (2012). Research advances in environmentally and socially sustainable operations. European Journal of Operational Research, 223(3):585-594.

Teuscher, P., Grüninger, B., and Ferdinand, N. (2006). Risk management in sustainable supply chain management ( $\mathrm{sscm})$ : lessons learnt from the case of gmo-free soybeans. Corporate Social Responsibility and Environmental Management, 13(1):1-10.

Tol, R. S., Yohe, G. W., et al. (2006). A review of the stern review. World Economics, 7(4):233.

UN (2017). Progress towards the sustainable development goals report of the secretary general. Technical report, United Nations Economic and Social Council.

UNEP (2010). Assessing the environmental impacts of consumption and production: Priority products and materials. a report of the working group on the environmental impacts of products and materials to the international panel for sustainable resource management.

Vaidya, O. S. and Kumar, S. (2006). Analytic hierarchy process: An overview of applications. European Journal of operational research, 169(1):1-29. 
van de Vijver, M. A. R. et al. (2009). Collaboration in buyer-supplier relationships. CentER, Tilburg University.

WEF (2015). Global risks 2015. Technical report, World Economic Forum.

WEF (2017). Global risks 2017. Technical report, World Economic Forum.

Wehn, U. and Montalvo, C. (2018). Exploring the dynamics of water innovation: Foundations for water innovation studies. Journal of Cleaner Production, 171, S1-S19.

Weitzman, M. L. (2007). A review of the Stern Review on the economics of climate change. Journal of economic literature, XLV:703-724.

WHO and Unicef (2016). Who/unicef joint monitoring programme (jmp) for water supply and sanitation. Technical report, World Health Organization and Unicef.

Wind, Y. and Saaty, T. L. (1980). Marketing applications of the analytic hierarchy process. Management science, 26(7):641-658.

Xu, M., Li, C., Wang, X., Cai, Y., and Yue, W. (2018). Optimal water utilization and allocation in industrial sectors based on water footprint accounting in dalian city, china. Journal of Cleaner Production, 176:1283-1291.

Zabarenko, D. (2011). Water use rising faster than world population.

Zahedi, F. (1986). The analytic hierarchy process - a survey of the method and its applications. interfaces, 16(4):96-108.

Zanabria, C. (2017). Water shortage to affect industrial output: Experts. El Comercio, Peru, https://elcomercio.pe/peru/arequipa/escasez-agua-potable-afecta-poblacionarequipa-407907(Last Accessed: 30/12/2017).

Zeng, Z., Liu, J., Koeneman, P., Zarate, E., and Hoekstra, A. Y. (2012). Assessing water footprint at river basin level: a case study for the heihe river basin in northwest china. Hydrology and Earth System Sciences, 16(8):2771.

Zimmer, K., Fröhling, M., and Schultmann, F. (2015). Sustainable supplier management - a review of models supporting sustainable supplier selection, monitoring and development. International Journal of Production Research, 54(5):1412-1442. 